\title{
El ser irreal y el ser ideal en Salazar Bondy
}

\author{
The unreal being and ideal in Salazar Bondy
}

\author{
Ernesto Walter Llanos Argumanis ${ }^{1}$
}

\begin{abstract}
Resumen
El presente artículo tiene por objetivo presentar panorámicamente una pequeña crítica sobre el texto de Augusto Salazar Bondy, Idealidad e Irrealidad. Así, hemos dividido esta sección en dos partes: la primera que versa sobre algunos aspectos importantes acerca del ser ideal y el irreal y la segunda que plasma la crítica que le hacemos al texto.
\end{abstract}

Palabras clave: idealidad; irrealidad; Salazar Bondy.

\begin{abstract}
This article presents the analysis and contrast to the development of the argument of the post grade thesis of Salazar Bondy about Ideal objets and Unreal objects .this article have two parts, the first one describe the most important concept about the ideal and unreal object or ideas and the second parte we give you our critical opinion again, respectable to point of view of Salazar Bondy.
\end{abstract}

Keywords: ideality; unreality;Salazar Bondy.

\section{Introducción}

El presente trabajo es un análisis crítico y hermenéutico de un concepto derivado de la concepción husserliana, que presenta muchas dificultades. En primer lugar, un conjunto de conceptualizaciones de términos importantes que sirven de ruta para llegar a un segundo momento donde se esboza un marco teórico y conceptual que puede servir para ubicarnos en el terreno de la irrealidad teniendo por lo menos algunas referencias a la intuición, la realidad, idealidad, noema y noesis. Para así, de manera más segura dar el siguiente paso. Tambien se revisó los términos de idealidad e irrealidad en la tesis de doctorado realizada por Augusto Salazar Bondy de una manera muy sucinta con un primer análisis crítico e interpretativo sobre la obra, para luego pasar a la última parte de este trabajo. Para culminar se realizó un conjunto de cuestionamientos con el fin de ampliar y reformular problemas, en base a varias miradas de distintos autores, que permitan futuras investigaciones en la extensa exploración que tiene por delante la visiones sobre fenomenológia y su recepción en la tradición del pensamiento filosófico peruano a lo largo del siglo anterior (siglo XX).

\section{Materiales y métodos}

El lugar de ejecución de la presente investigación es la problemática de los conceptos idealidad e irrealidad trabajado por Augusto Salazar Bondy en su tesis de doctorado. La metodología está basada en un enfoque cualitativo, ya que busca comprender las dimensiones interpretativas de estos conceptos, teniendo en cuenta sus raíces en la fenomenología y en la ontología a su vez de plantear las posibilidades en el contexto de la filosofía peruana. En el diseño de investigación, el trabajo se define como interpretativo porque se usa un enfoque multidimensional para realizar un análisis crítico, comparativo y hermenéutico sobre la problemática conceptual de la idealidad e irrealidad en Augusto Salazar Bondy y sus posibilidades en la filosofía peruana, a partir de su tesis de doctorado tomando como referencias las manifestaciones sobre estos términos de la fenomenología y la ontología previa a este autor. Para ello se usarán algunas categorías de la ontología filosófica a fin de realizar los análisis comparativos, interpretativos y sus probabilidades.

\section{Resultados y discusión}

\subsection{Consideraciones Terminológicas}

Hemos decidido iniciar este trabajo realizando una serie de definiciones que nos ayudarán a comprender mejor algunos conceptos, pero además nos permitirá establecer un camino por el cual podremos formular con mayor sustento una serie de cuestionamientos acerca del concepto de la irrealidad el cual es el eje principal de la presente reflexión.

\section{Experiencia}

Husserl (1999) plantea la experiencia como principio y base del conocimiento, y busca un método distinto al científico para determinar la experiencia, desbordando la postura kantiana que toma la experiencia sólo desde un punto 
de vista gnociológico para fundar su ontología. Por esto Husserl "Se reprochaba a Kant el no haber logrado exponer una teoría "pura" del conocimiento, libre de todo elemento naturalista. En este sentido, Hussel intento realizar, a su manera, y por medio del método fenomenológico, aquello mismo en que había fracasado Kant"(Farber, 1956). Esta es una de las razones por la cual Husserl amplía el concepto de experiencia a todos los ámbitos de la vida humana. Sobre la concepción de la experiencia diremos en líneas generales que:

En el hombre se ve que el locus de la experiencia está en su interacción con la naturaleza y con los demás hombres. El proceso de la experiencia ocupa una parte infinitesimal del cosmos, y sólo se produce cuando interviene en la acción seres sensibles. La experiencia está en la naturaleza, y sencillamente no es verdad que la naturaleza esté en la experiencia.

Las condiciones causales de la experiencia son de carácter físico, orgánico y cultural. La experiencia real tiene ciertamente "límites". La experiencia es siempre selectiva y, como ha observado Husserl, nunca se podrá concebir una percepción que contemple todos los lados ("la percepción quiere más de lo que puede abarcar", como dijo con expresión característica). Pero ello , no implica que exista algún campo cualitativamente trascendente. Hay siempre "más" de la misma especie de rasgos experimentados, pero solo prueba un "más allá" que sea distinto por principio del mundo de la experiencia (Farber, 1956).

Finalmente afirmamos que para Husserl en el mundo no hay más que experiencia, pero esta comprende mucho más que el ámbito empírico.

\section{Percepción}

Teniendo en cuenta la ampliación de la experiencia realizada por Husserl, es comprensible que la percepción, el modo de captar la realidad o el mundo, comprende dos vías la empírica y la eidética a la cual denomina intuición. La Percepción empírica, es la captación de la realidad por medio de los sentidos. Mientras la Percepción eidética o intuición, es el medio o facultad de captar la unidad ideal (esencias) como atributo que constituye la igualdad, en la comparación. Es una captación directa de las esencias.

En relación a la intuición podemos apreciar como Husserl atribuye a las "Descripciones eidéticas de experiencia constitutiva vienen a ocupar el lugar de la realidad física" (Farber, 1956). Partiendo de esta suposición podría interpretarse que la base del conocimiento, al parecer, sería la experiencia eidética y no la empírica o tal vez ambas.

La percepción está vinculada con el tiempo, sobre esto describe Huserl en La fenomenológica del tiempo inmanente. En el texto se presenta la percepción actual, que la relación entre pasado y presente como una captación continua. La percepción es reunir una continuidad de caracteres de acto, es límite ideal. Aparte realiza otra clasificación de la percepción:
A) Adecuada. Como darse inmanente y adecuado darse del objeto.

B) Inadecuada. Toda percepción es inadecuada, a causa del tiempo que es como un eterno fluir.

Sobre estas formas de intuición podemos agregar que “... aquella que permanece constante o cambia, permite su intuición adecuada de la segunda especie de percepción, pero no puede designarse como momento o trazarreal- inmanente a ella" (Husserl, 1959). A pesar de esta distinción teniendo encuesta lo descrito en Ideas I solo hay percepciones más claras u oscuras nunca se logra las intuiciones completamente adecuadas sólo perspectivas.

\section{Representación}

Según las investigaciones lógicas husserlianas, la representación es la imagen producto del acto de representar. Aquírepresentar es el acto dondela Imagen-objeto se devela en la conciencia. Existen varios modos de representar, por eso es importante "...que en la representación imaginativa mentamos el objeto representado en la imagen (el sujeto de la imagen) fundándonos en el objeto imagen aparente." Husserl (1959) básicamente distingue entre representación intuitiva y pasiva.

La imagen en la representación es definida de la siguiente manera "La imagen sólo se torna imagen por la facultad que un yo representante tiene de servirse de lo semejante como representante imaginativo de lo semejante, de tener presente intuitivamente tan solo una cosa y mentar otra en lugar de ella" (Husserl, 1999). Representando un objeto determinado en un acto interno.

Husserl también nos dice que "La imagen se constituye como tal en la conciencia intencional. peculiar y en el carácter interno de este acto, la peculiaridad especifica de este "modo de apercepción",...". y "el objeto intencional de la representación es el mismo que su objeto real y dado el caso- que su objeto exterior, y es un contrasentido distinguir entre ambos."(Husserl, 1999). Es decir que el objeto representado intencional es el objeto de la representación.

\section{Realidad}

Para no extendernos demasiado sólo referiremos a lo dado, los hechos que se presentan, los fenómenos que forman parte de las vivencias en la actitud natural. El mundo existente, que contiene los objetos reales, materiales, dados en el espacio y en el tiempo que constituye toda la corriente de experiencias en el ámbito trascendente (fuera del sujeto o de la inmanencia).

\section{Idealidad}

En primer lugar diremos que la idealidad comprende "El ser como mera idea o representación (vorstellung), en contraposición a la realidad, al ser en la realidad objetiva (objetive wirklichkeit), Riso-Patrón de Lerner, 1993. Este tema es desarrollado por Husserl en Investigaciones 
lógicas teniendo en cuenta esto podemos complementar la definición de idealidad con otros conceptos afines como:

A)Unidad Ideal de la significación. Relacionado con el carácter de acto que tiene el significar. Es el modo de conciencia nueva por el cual se hace presente la especie (una característica de un objeto como la rojez) en lugar de lo individual (el objeto rojo). "La significación como especie se produce, pues, por abstracción ${ }^{2}$ sobre la base indicada de objetos individuales. Por eso la lógica pura distingue entre objetos individuales y universales. De esta consideración se deriva primero que el objeto ideal es el objeto específico. En segundo lugar el problema de la abstracción de la intuición eidética.

B) Idealismo. Forma epistemológica que reconoce lo ideal como condición de posibilidad del conocimiento objetivo sin psicologismos.

C)Objeto ideal. Son las posibilidades, pero también lo "Mentado" es lo "universal", la unidad ideal y no las singularidades, no los muchos. Objetos universales, inespaciales y atemporales que son en sí mismos y no dependen de una psiquis como caracteriza Salazar Bondy (Salazar, 1958).

D)Ideación. Formación de Ideas que descansa sobre intuiciones conservadas en la mente. Conceptos; llamado también: abstracción ideatorea (ideierende Abstraktion); también: visión de esencias (UNMSM, 1958).

\section{Irrealidad}

Para empezar podemos decir que la irrealidad es un predicado o también una categoría para designar objetos no reales, imaginados, ideales, etc. Se dice que estos objetos no existen al no ser materiales y no tener relación ni con el espacio ni con el tiempo. Y caracterizados por intencionalidad.

Husserl en sus Investigaciones lógicas como parte de un proceso de desarrollo considera que "No hay gradación capaz de establecer términos medios entre lo ideal y lo real" (Husserl, 1999), pero en su texto de Ideas describe todo un campo de relaciones entre el sujeto y el objeto que es lo que podríamos llamar irrealidad.

\subsection{EI Ser Irreal y EI Ser Ideal En Salazar Bondy}

Ahora pasaremos a presentar panorámicamente una pequeña crítica e interpretación sobre el texto de Augusto Salazar Bondy, Idealidad e Irrealidad.

Así, hemos dividido esta sección en dos partes: la primera que versa sobre algunos aspectos importantes acerca del ser ideal y el irreal en el texto referido y la segunda que plasma la crítica e interpretación que le hacemos al texto.

\section{El Ser Irreal}

División del ser irreal. Según Salazar Hartman distingue los siguientes tipos de irreal puro:
A) La esfera del pensamiento. A esta esfera pertenecen los objetos de los sistemas de pensamiento. Ejemplo: la multiplicidad de imágenes del mundo que ofrece la filosofía.

B) Las estructuras imaginativas de toda especie y todo matiz. Los objetos irreales de este tipo fundan su ser en la elaboración espontánea de la fantasía. En su contenido frecuentemente se da una penetración particular de estructuras ideales y en su construcción una adecuación primera a las leyes lógicas. Por ejemplo una historia de fantasía pero con una estructura narrativa coherente.

C) Los contenidos de los sueños y las alucinaciones. Productos de los procesos mentales inconscientes.

D) Irreales ligados a un ser en sí de valor. Tal es el caso de las ideas, los "ideales", las concepciones artísticas, los objetos de los anhelos, los fines propuestos, los ideales de vida que se forma un sujeto. Los contenidos de las concepciones mitológicas y religiosas. Ideales políticos, jurídicos y las utopías sobre una organización mejor de la vida humana.

E) Las cualidades sensibles de los objetos irreales y las leyes que las caracterizan. Son las características imaginarias, texturas, colores, sabores, formas de organización e interrelación de todos los tipos de elementos irreales mencionados previamente.

Clasificación de los entes irreales. En primer lugar por la consistencia de los términos intencionales.

Clases de irreales atendiendo a la materia de los términos intencionales mismos.

A) Irreales que no se dan en la conciencia mediante determinaciones sensibles. Sino más bien inteligibles (intelectuales) A esta categoría pertenecen los objetos irreales del pensamiento.

B) Irreales que se dan en la conciencia mediante determinaciones concreto-sensibles. En estos casos sin efectivo carácter perceptivo. Tales como, los objetos de la fantasía, del sueño, de las alucinaciones, también las estructuras de la imaginación y los objetos de las concepciones mitológicas.

C) Irreales que se dan a través de una materia perceptiva. Objetos vistos en las manchas, en las llamas, etc. (Ilusiones ópticas)

\section{Caracterización de los entes irreales:}

A) El ser intencional. Los objetos ideales carecen de ser en sí, no son trascendentes al acto, dependen de él y a él como algo psíquico, ni en la realidad, ni en el mundo de las conexiones ideales. Su ser no reposa en sí mismo. $\mathrm{Su}$ ser se agota en la intención de una vivencia, que nace y muere con ella.

B) Los entes irreales no son objetos propios de conocimiento. Por su carácter intencional lo irreal no puede entrar en la conexión del conocimiento. 
C) EI ser por sí. El objeto irreal se agota en el acto y no rebasa la intención que apunta a él, carece de ser en sí, pero posee ser por sí, tiene una función o finalidad y por ello vinculado directamente con lo relacional, depende de la relación con una intención o deseo.

\section{El Ser Ideal}

La evidencia del intuir eidético y la necesidad del ser ideal:

A) Las conexiones esenciales y la evidencia apodíctica como hilos conductores para descubrir la idealidad. Existen dos tipos de intuiciones, a saber: la intuición eidética y la intuición empírica. A la primera le corresponde una evidencia apodíctica y, a la segunda le corresponde un ver asertórico. Ahora bien, el intuir esencial posee un rasgo de certidumbre. En efecto, las esencias, están constituidas por determinaciones constantes, entre las que se establecen conexiones necesarias. Por el contrario, el intuir empírico debe mostrarse necesariamente adecuada a las ciencias eidéticas, ya que su negación constituye un contrasentido material. El criterio diferencial que necesitamos para distinguir los dominios de ser Ideal y del ser Irreal, son proporcionados por la invariancia del contenido de las esencias, la conexión necesaria de sus notas y la evidencia apodíctica de su aprehensión. Desde la nueva perspectiva que nos abre esta consideración, el ser Irreal ya no puede confundir sus estructuras con las del ser Ideal. Ambas quedan claramente enfrentadas: de un lado conexión necesaria, de otro, conexión contingente. Con esto tendríamos a nuestro alcance un preciso criterio diferencial, que permitiría el siguiente ordenamiento de los entes: entes irreales, que son dependientes del sujeto y contingentes; entes reales, que son independientes del sujeto pero son contingentes, y entes ideales, que son independientes del sujeto y necesarios.

B) Crítica de la fundamentación husserliana de las conexiones eidéticas y la evidencia de su aprehensión. Disciplinas eidéticas son, las matemáticas, la ontología general, las ontologías regionales y las ciencias descriptivas de esencias y, finalmente, la fenomenología de las vivencias puras. Estas últimas, se hallan lejos de haber conformado un cuerpo de conocimientos firmes. En efecto, las ciencias eidéticas materiales, relativas a los dominios que estudian las empíricas, deben proporcionar, un sistema de principios sintéticos "a priori", en los cuales el trabajo de la investigación empírica habría de encontrar el cimiento de validez universal que le falta. Por lo que toca a las existencias reales, este tener que existir es la consecuencia de la conexión esencial y no su contenido mismo. Pero esta conexión ¿Qué es ella misma? En cada de estas intuiciones particulares, las esencias respectivas se dan libres de relación entre si, separadas, independientes en suma. Por lo tanto se mostró primero que el enfrentamiento del ser en sí de lo ideal y el ser simplemente intencional de lo irreal no podía ser probado a base del examen del modo de dación de ambos tipos de objetos, porque en ambos casos los rasgos fundamentales de los actos eran coincidentes. En segundo lugar, se apelo a la correspondencia con lo real que, por convenir a ciertos objetos ideales, podía servir de hilo conductor para la determinación de su ser en sí. Recurrimos entonces a la distinción entre la invariancia de las determinaciones ideales y la variación de las estructuras irreales, enfrentando en el seno mismo de los objetos irreales un núcleo esencial y un margen irreal, enfrentamiento que habría de explicar la semejanza de la dación de lo irreal y lo ideal. Pero este tercer recurso tropezó con las dificultades provenientes de la imposibilidad de distinguir los concretos irreales y las singularidades eidéticas, así como también de la existencia de una ordenación de géneros y especies tanto en el mundo irreal como en el ideal. Finalmente, examinamos el intento de fundar la diferenciación de los dos tipos de ser sobre la base de la distinción entre la necesidad de las conexiones eidéticas (que convendría a los entes ideales) y la contingencia de las estructuras objetivas irreales. Esta distinción se ha mostrado insostenible en lo que toca a las conexiones materiales, porque tales conexiones, tanto en el orden de las esencias morfológicas (estudiadas por las ciencias descriptivas) cuanto en el de las exactas (estudiadas por las matemáticas), carecen de auténtica necesidad interna y deben ser consideradas como contingentes. $\mathrm{Si}$ a todo ello se agrega que los principales rasgos constitutivos de los objetos ideales (como son la intemporalidad, la inespacialidad, la universalidad, etc.) pertenecen también a los objetos irreales, parecen necesario extraer la consecuencia de que ambos tipos de objetos no conforman sino uno solo y que ambos, en cuanto posibilidades libres de variación de contenidos objetivos, se enfrentan a las estructuras formales mentadas en los principios ontológicos supremos. Cuando se toma conciencia de que estas ciencias tienen su punto de partida en una definición libre de sus objetos, ya no puede parecer extraño que aprehensión de objetos ideales y vivencia imaginativa sean parientes y que correlativamente, sus objetos lo sean igualmente. La conciencia aprehende estructuras objetivas en la realidad a través de los actos de conocimiento que dan originariamente objetos reales, es decir, en principio, los perceptivos. Sin embargo, puede sufrir una modificación particular. El sujeto es capaz de desviar la mirada del objeto real en su singularidad y, sea a base de la consideración de una pluralidad de objetos semejantes, sea por una suspensión de la posición de existencia fundada en la dación de un solo objeto real, dirigirla a la nada consistencia óptica del ente, a la unidad de las determinaciones que lo integran. Al efectuar esta acción ente real sino su simple virtualidad "lógica", que se le enfrenta como una síntesis particular de elementos objetivos. Actos del primer tipo son los de la abstracción y de la generalización, en los que la 
conciencia aprehende universales, según la doctrina tradicional, y la ideación que conduce a las esencias, en el sentido de Husserl, gracias a los cuales, objetos como mesa, color, triángulo, son captados como géneros puros. Pero también aquellos en que, a base de contenidos perceptivos, se intuye un objeto artístico, como una sonata, un paisaje o una obra teatral. Actos del segundo tipo son aquellos en que se comparan diversos individuos reales, géneros y especies, y se notan las semejanzas de contenido y organización estructural, como por ejemplo, diversas Figuras geométricas, plantas, rostros, etc. Pertenecen al tercer tipo los actos de constitución de entes matemáticos, como un polígono de mil lados o la estructura objetiva a que se refiere el postulado de las paralelas en geometrías riemannianas; las especulaciones filosóficas sobre la conciencia trascendental o la república ideal; la elaboración.

\section{El ser intencional de los objetos irreales y el ser en si de los objetos ideales:}

Para ser el objeto irreal necesita de la intención y no va a poseer más ser que el que la mención le confiere, este intuir se da por reiteradas aproximaciones del propio intuir en el cual el objeto se enriquece, la intención recubre completamente el contenido objetivo del ente, pero ella no lo aprehende al ente nace con la mención y se conforma a ella por el contrario el ser en si del objeto ideal se verifica a través del paso de la intención vacía a la impleción (RisoPatrón de Lerner. 1993) 3 y eventualmente por la asunción de un plus de caracteres que son descubiertos en el proceso de captación el objeto irreal no posee ser en sí, solo sus intuiciones.

Existe un paso en el cual el sujeto no recrea mediante la intención los objetos de un ensueño pasado sino que solo fija contenidos ya establecidos, se remite solo a inspeccionar, aceptar o rechazar cosas de él, este ente se le ofrece provisto de cierta independencia por lo expuesto se puede decir que son vivencias de conocimiento de descubrimiento por decirlo así, se puede aceptar que la aprehensión de un objeto irreal ofrece caracteres semejantes a la del ideal pero siempre y cuando no se tome en cuenta el hecho de que el acto imaginario de mención del irreal es siempre una vivencia de creación por que el sujeto lo adecúa a una estructura objetiva pero igual, el sabe que si lo ve (en la imaginación) este igual es puesto por el.

\section{Conclusiones}

Salazar determina como existente aquello que esta relacionado con lo real, por lo que los objetos irreales e ideales son inexistentes. ¿Pero es adecuado restringir la existencia solo a lo material?

Utiliza los términos esencia, eidos y objeto ideal como referencias al ente ideal que para Salazar son externos al sujeto; si esta afirmación es correcta ¿Qué fundamento tiene ${ }^{3}$ Impleciòn significativa o pensamiento intuitivo, proceso mental donde se intuye la esencia de un objeto. para afirmar que son externos al sujeto e independientes de éste? y en esa medida las características de este ente ideal parecen ser determinaciones necesarias forzadas por la teoría de Salazar, basado en las investigaciones de Husserl y Hartaman.

Estos objetos ideales son captados a través de una intuición eidética que es a priori al sujeto, en esta medida existe una relación apriórica entre el sujeto y los entes ideales. Sin embargo es el ente ideal el que no puede ser modificado por aquél sujeto. Pero teniendo en cuenta la teoría kantiana cabe preguntar ¿Cómo es posible hablar de intuición eidética sin un nexo con la realidad empírica?

Paralelamente Salazar remite al desarrollo del ente irreal imaginario, fantástico y ficticio que se refiere indirectamente a ciertos actos que por voluntad del sujeto son captados. En esa medida el sujeto crea este tipo de entes. Así los sistemas filosóficos también se encuentran clasificados como entes irreales, que diferenciándose de los imaginarios y de las fantasías serían manifestaciones de la realidad ¿Cómo en esa medida pueden ser los sistemas filosóficos clasificados como no existentes? Y lo mismo los entes mitológicos, puesto que estos al ser concebidos por los sujetos de aquellos tiempos antiguos ¿no lo determinaban como no existentes o reales en su contexto?

\section{Literaura citada}

Farber, M. 1956. Husserl. Buenos Aires, Losange.

Husserl, E. 1959. Fenomenología de la conciencia del tiempo inmanente. Buenos Aires, Nova.

Husserl, E. 1999. Investigaciones lógicas. Tomo 1. Madrid, Alianza Editorial, S.A. Pág. 80.

Riso-Patrón de Lerner, R. Ed.1993. El pensamiento de Husserl en la reflexión filosófica contemporánea. Lima, Pontificia Universidad Católica del Perú. Instituto Riva Agüero. Pág. 330.

Universidad Nacional Mayor de San Marcos. 1958. Irrealidad e idealidad. Editorial San Marcos Lima. $147 \mathrm{p}$. 